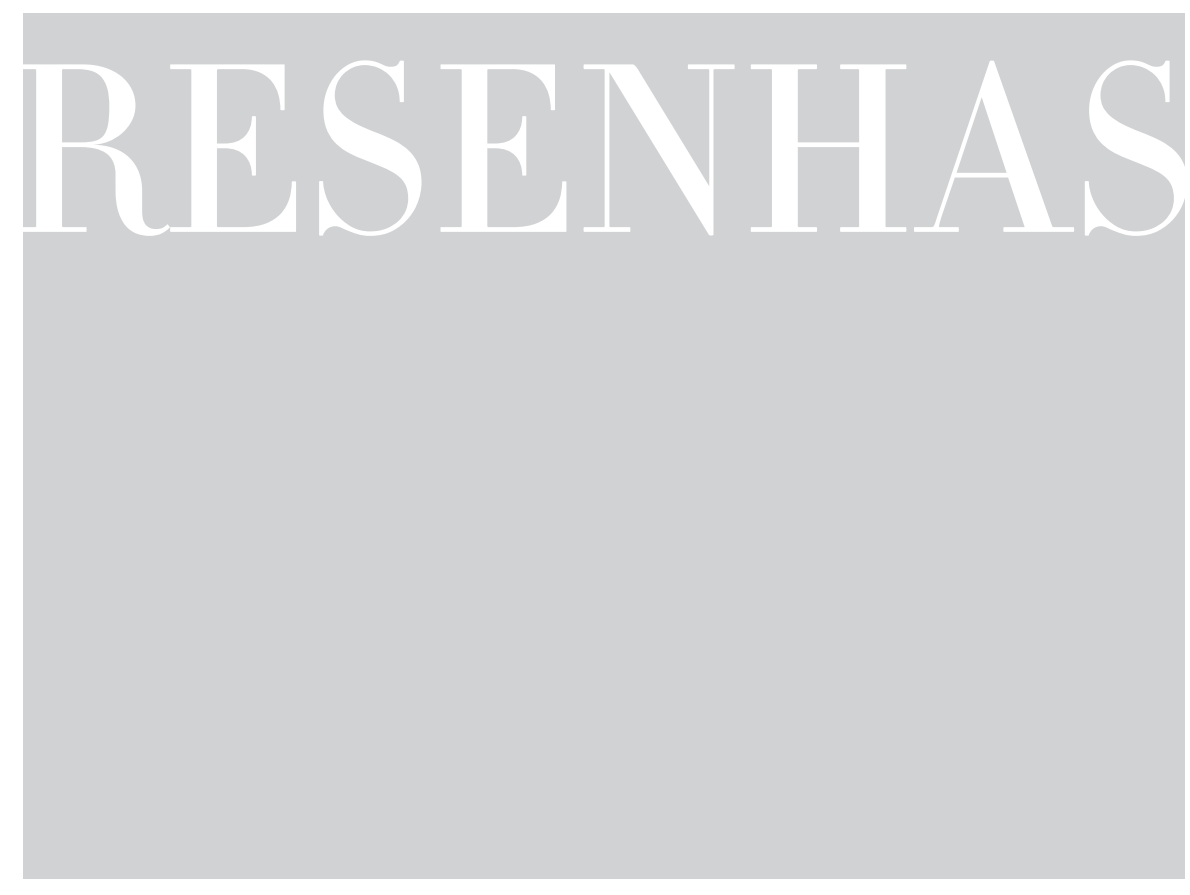

\title{
POR QUE AS CRIANÇAS OBEDECEM AUTORIDADES E SEGUEM REGRAS?
}

https://doi.org/10.1590/198053145532

\section{HERBERT RODRIGUES'}

TYLER, Tom R.; TRINKNER, Rick. Why children follow rules: legal socialization and the development of legitimacy. New York: Oxford University Press, 2017. 280 p.

Em época marcada pela desconfiança generalizada nas instituições e autoridades, o tema da obediência poderia causar estranhamento e certo ruído no debate público atual. Mas não há questão mais central nas ciências sociais do que entender as razões pelas quais os indivíduos obedecem às figuras de autoridade e seguem as leis na maior parte do tempo e não o contrário. A pergunta que se coloca então é saber por que obedecem e qual o conteúdo dessa obediência? Essas são as principais questões debatidas no livro Why children follow rules: legal socialization and the development of legitimacy [Por que as crianças seguem regras: socialização legal e desenvolvimento da legitimidade, em tradução livre], escrito por dois psicólogos sociais norte-americanos, que lança olhar na formação das noções de regras pelas crianças.

O livro insere-se no campo de conhecimento da socialização legal. Teóricos sociais clássicos como Freud, Piaget, Durkheim, Weber, Bourdieu, entre outros, abordaram a importância da socialização e da internalização de valores como instrumentos que efetivam o funcionamento da sociedade. Os estudos de socialização legal podem ser considerados um subconjunto da discussão mais ampla de socialização, voltados 
para a compreensão das regras e leis como organizadores racionais de condutas e comportamentos dos indivíduos. A socialização legal define-se como processo pelo qual os indivíduos aprendem as regras formais e informais da sociedade e desenvolvem relações com a lei. E a passagem da infância para a adolescência consiste em período crucial de aquisição de valores legais.

O livro propõe uma extensa revisão da literatura para demonstrar o que funciona e o que não funciona no processo de socialização legal das crianças. Apesar do aparente caráter teórico, os autores apresentam inúmeras evidências empíricas calcadas em décadas de pesquisa. A obra esclarece que o comportamento das principais figuras de autoridade responsáveis pela socialização legal (pais, professores e autoridades legais, incluindo a polícia) afeta a maneira pela qual as crianças respondem mais tarde na vida adulta em termos de compreensão do ordenamento legal e de obtenção legítima da obediência.

A obra focaliza a análise em três instituições fundamentais com as quais as crianças e os adolescentes lidam nas primeiras décadas de vida: a família, a escola e o sistema de justiça juvenil. Nessas três esferas, há figuras com posturas distintas que exercem o papel de autoridade. Apesar das diferenças e distâncias entre as autoridades, suas ações contribuem decisivamente no processo de socialização legal das crianças, com consequências na vida adulta em relação às leis. Assim, as figuras de autoridade atuam de maneira relacional na criação de laços sociais e de confiança nas instituições. Uma mesma criança pode ter contatos com estilos diferentes de autoridade que fortalecem, ou minam, a formação de atitudes e valores legais e igualmente transmitem visões positivas, ou negativas, dos valores das regras e leis.

Desse modo, a atuação das figuras de autoridade não consiste somente em estabelecer regras e exigir obediência, mas também opera como modelo para as ações das crianças em relação ao mundo legal a partir da natureza do tratamento proporcionado. As evidências apresentadas pelos autores apontam que o tratamento digno e respeitoso gera legitimidade e confiança, além de elevar o nível de cooperação e obediência. Em compensação, o tratamento autoritário, inconsistente e arbitrário de impor e sustentar regras tende a gerar cinismo legal. As consequências dessa atitude incidem no aumento da possibilidade de burlar as regras e também elevam as chances de que atos infracionais sejam perpetrados no futuro.

Segundo os autores, há duas maneiras básicas de obter obediência dos adultos: pela coerção ou pelo consentimento (TYLER; TRINKNER, 2017). A primeira ocorre quando obedecemos às leis em grande parte devido às ameaças de sanções e por temor às penas impostas pelo aparato do sistema de justiça criminal. A segunda ocorre porque somos ensinados a obedecer não por medo, mas, ao invés disso, pelo senso de 
responsabilidade e de dever percebidos como membros de uma sociedade mais ampla. Nesse sentido, seguimos as regras porque acreditamos no aparato normativo de regulação e nas autoridades responsáveis pela aplicação e manutenção das regras e leis.

Os autores reconhecem que a obtenção da obediência por meio da coerção ocorre com frequência, mas os custos sociais de manutenção do aparato coercitivo apresentam-se elevados, ineficazes e não produzem mudanças. E, mesmo quando a coerção funciona, os efeitos são breves, temporários e não geram confiança. O sistema consensual, por sua vez, é eficiente por facilitar o entendimento dos valores que devem prevalecer numa sociedade democrática e por fortalecer a confiança nas autoridades e nas instituições.

O argumento central do livro está na maneira como as autoridades devem agir para formar nas crianças as noções de regras; como os pais devem educar os filhos; como os professores devem se comportar e desempenhar suas funções; e o mesmo ocorre para o sistema de justiça e a polícia. A ênfase recai não somente na qualidade do procedimento das autoridades no momento de interação direta, mas também no modo como os indivíduos interpretam essas experiências e interações.

O livro é composto por nove capítulos distribuídos em três partes. A primeira tem caráter geral e introdutório e apresenta os principais conceitos e elementos da socialização legal como campo de investigação e, simultaneamente, processo contínuo de aprendizagem que se desenvolve ao longo da vida. A segunda parte trata de modelos teóricos de análise da socialização legal, com foco nas análises de desenvolvimento de competências, atitudes e raciocínios, incluindo a abordagem da neurociência, voltados ao entendimento das regras e leis. A terceira parte enfoca diferentes esferas da infância e da adolescência (a família, a escola e o sistema de justiça) e lança mão do conceito de justiça procedimental. Os autores indicaram os pais, os professores e os agentes da lei como as principais autoridades responsáveis pelo processo de socialização legal, por entenderem que o procedimento dessas três figuras contribui decisivamente na formação e fortalecimento da legitimidade das regras e da obediência por consentimento.

São identificados três elementos-chave em relação à justiça procedimental das autoridades. O primeiro refere-se ao estabelecimento de vínculos afetivos entre pais e filhos e à promoção de comportamentos parentais que demonstrem cuidado, preocupação e responsividade. $\mathrm{O}$ segundo é a maneira pela qual os pais tomam decisões, aplicam as regras e regulam as violações dessas regras, incluindo as tentativas de envolver ativamente os filhos no processo de aplicação de regras justas e neutras (as opiniões das crianças devem ser consideradas no momento que os pais tomam as decisões). Por fim, os pais devem reconhecer e negociar os limites de sua autoridade em determinados domínios pessoais, 
a fim de favorecer a autonomia dos filhos e garantir o respeito às regras (as crianças demarcam a vida a partir de domínios e reconhecem que as autoridades têm o direito de regular algumas áreas do comportamento, mas não todas).

Em relação às escolas, as observações são muito parecidas com as da família. À medida que os alunos veem seus professores como legítimos, o sentimento de aceitação da autoridade aumenta. Assim, os alunos são mais propensos a respeitar a autoridade e obedecer às regras por meio de tratamentos dignos e respeitosos. Além disso, ao imporem punições justas, os professores adquirem legitimidade e confiança.

Finalmente, em relação às autoridades e instituições legais, os autores afirmam que as crescentes abordagens punitivas do sistema de justiça juvenil tendem a minar a legitimidade e, consequentemente, a elevar o cinismo legal e a prática de atos infracionais. O exercício coercitivo das autoridades, baseado em punições, não permite aos agentes da lei, em especial a polícia, nenhum outro meio de fazer o indivíduo seguir suas ordens além do uso da força. Em última análise, a maneira como os filhos e os alunos são ensinados tem impacto direto nas visões acerca das regras e leis.

A leitura do livro evidencia que a socialização legal baseia-se num processo relacional. Os autores afirmam que na família as crianças aprendem os primeiros elementos sobre obediência e respeito às regras e autoridades. E o papel que as escolas desempenham como força socializadora forma os modelos pelos quais os indivíduos vão pensar e interagir com o sistema de justiça no futuro. Portanto, a primeira esfera na qual as crianças se tornam legalmente socializadas está sob a alçada dos pais e de outros membros da família. No sistema de educação formal, há expectativa de que os professores exerçam um papel decisivo no processo de socialização legal, em grande parte por conta das semelhanças do exercício da autoridade entre pais e educadores nos primeiros anos escolares.

É importante ter em mente que socialização legal não se configura como via de mão única. A interação das crianças com as autoridades pode ser entendida como momento de aprendizagem. Na medida em que essas interações são vistas como justas e legítimas, os valores legais tendem a se reforçar. Em compensação, a exposição dos indivíduos tanto a decisões arbitrárias (direta ou indiretamente) das autoridades quanto a ações consideradas injustas pode prejudicar a orientação para as leis e reforçar a percepção de que o sistema de justiça não funciona igualmente para todos. Segundo Rodrigues et al. (2017, p. 113), “as decisões individuais em obedecer e colaborar com as normas e as leis são baseadas nas crenças construídas ao longo de toda a vida por meio de contatos com as autoridades". 
Além disso, a socialização legal não consiste somente em teoria, campo de pesquisa ou manual prescritivo de comportamento para as autoridades; incide, sobretudo, em resultados práticos nos gastos que a sociedade despende para sustentar o sistema de controle e vigilância. Quando os indivíduos obedecem legitimamente às leis e às autoridades, os recursos públicos utilizados para a manutenção do aparato de repressão podem ser realocados em outros empreendimentos sociais.

Como já foi dito, os autores apresentam ao longo da obra uma extensa e cuidadosamente elaborada revisão da literatura e citam centenas de trabalhos. Uma sugestão, em caso de tradução e publicação no Brasil, é que as referências bibliográficas sejam reorganizadas em forma de bibliografia comentada, a fim de facilitar a consulta. Escrito em linguagem simples e acessível, o livro pode ser lido por pais, educadores e profissionais nas áreas relacionadas à proteção da infância e juventude. A leitura do livro oferece base suficiente para o entendimento do campo da socialização legal e pode desencadear ações concretas por parte das autoridades.

Mesmo não mencionando o Brasil, o livro fornece combustível para alimentar o debate sobre a socialização das crianças para as regras e os comportamentos dos adultos em relação às leis em nosso país. Podemos imaginar, por exemplo, a leitura e discussão ocorrendo em cursos de pedagogia, psicologia da educação e licenciatura. Ou mesmo sendo utilizado em reuniões pedagógicas nas escolas, em treinamentos de agentes responsáveis pela elaboração de políticas públicas de proteção e assistência à infância e até mesmo por pais preocupados com a educação dos filhos em relação ao mundo legal.

Para as pessoas interessadas no tema, existem alguns trabalhos-chave que demonstram o desenvolvimento dos primeiros estudos de socialização legal até discussões mais recentes que ressaltam o papel da escola e do sistema de justiça como instituições responsáveis pela aprendizagem das leis (TAPP; LEVINE, 1974; COHN; WHITE, 1990; FAGAN; TYLER, 2005; JUSTICE; MEARES, 2014). Além disso, baseando-se em publicações recentes, fruto de resultados de pesquisa realizada pelo Núcleo de Estudos da Violência da Universidade de São Paulo, podemos afirmar que os estudos de socialização legal já ocorrem no Brasil (RODRIGUES et al., 2017; RODRIGUES; GOMES, 2017; THOMAS et al., 2018).

É importante frisar que a reflexão sobre as normas e, inclusive, a possível desobediência crítica a determinada regra ou lei considerada injusta e arbitrária também fazem parte do processo relacional entre indivíduos e autoridades. A socialização legal das crianças significa, sobretudo, a capacidade de se relacionar de maneira crítica com as regras criadas pelas autoridades.

Os autores lembram que a obediência pura e simples não é sinônimo de socialização legal. Isso significa dizer que não existe socialização 
legal completa que deu certo, de um lado, e socialização incompleta que deu errado, de outro. O foco não está na obediência em si, mas sim no que impele os indivíduos a obedecerem, ou seja, a motivação subjacente ao comportamento orientado para seguirem as regras e leis. E as pesquisas empíricas mobilizadas ao longo dos capítulos comprovam que a obediência por meio do consentimento torna-se mais efetiva e está relacionada aos valores das sociedades democráticas, ao possibilitar que as autoridades exerçam o poder legitimamente. Mas para que isso aconteça as crianças precisam aprender o que é uma autoridade legítima.

Podemos concluir que as discussões sobre socialização legal são cruciais numa época marcada pela baixa legitimidade das autoridades e pela desconfiança nas instituições. Assim, trata-se de apoiar ações que visam fortalecer o desenvolvimento da legitimidade ao longo das principais esferas da infância e adolescência. Qualquer coisa menos do que isso significa prejuízo para a efetivação dos valores democráticos.

\section{REFERÊNCIAS}

COHN, Ellen; WHITE, Susan. Legal socialization: a study of norms and rules. New York: Springer-Verlag, 1990.

FAGAN, Jeffrey; TYLER, Tom R. Legal socialization of children and adolescents. Social Justice Research, Thousand Oaks, CA, v. 18, n. 3, p. 217-241, 2005.

JUSTICE, Benjamin; MEARES, Tracey. How the criminal justice system educates citizens. The Annals of the American Academy of Political and Social Science, New York, v. 651, p. 159-177, January 2014.

RODRIGUES, Herbert et al. Socialização legal de crianças e adolescentes: revisão da literatura e desafios de pesquisa. Plural - Revista de Ciências Sociais, São Paulo, v. 24, n. 1, p. 105-123, 2017.

RODRIGUES, Herbert; GOMES, Aline M. M. Socialização legal e perfis de pré-adolescentes em São Paulo: uma análise de correspondência. Crítica e Sociedade - Revista de Cultura Política, Uberlândia, v. 7, n. 2, p. 181-206, 2017.

TAPP, June L.; LEVINE, Felice J. Legal socialization: strategies for an ethical legality. Stanford Law Review, Stanford, CA, v. 27, p. 1-72, 1974.

THOMAS, Kendra et al. Parental legitimacy, procedural justice and adolescent compliance among Brazilian preadolescents. International Journal of Child, Youth and Family Studies, Victoria, BC, v. 9, n. 3, p. 21-46, 2018.

TYLER, Tom R.; TRINKNER, Rick. Why children follow rules: legal socialization and the development of legitimacy. New York: Oxford University Press, 2017. 